\title{
In Memoriam
}

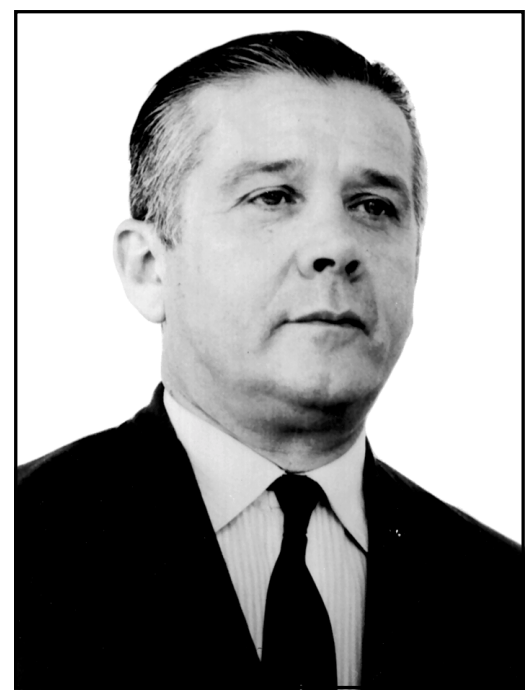

CARLOS DA SILVA LACAZ

(1915-2002)

Em 23 de abril de 2002, a Faculdade de Medicina da Universidade de São Paulo (FMUSP) perdeu um dos seus mais ilustres filhos, o seu arauto e guradiâo, o Prof. Dr. Carlos da Silva Lacaz. A perda atingiu toda a medicina brasileira e, com grande impacto, também a neurologia tropical.

Nascido em 19 de setembro de 1915 na cidade de Guaratinguetá (Estado de São Paulo), Lacaz graduou-se em medicina na FMUSP, em 1940. Na FMUSP, a Casa de Arnaldo, trilhou todos os passos de sua carreira universitária, iniciada antes mesmo de sua graduação, atingindo o cume com a conquista da posição de Professor Catedrático de Microbiologia e Imunologia, em 1953. Sua aposentadoria ocorreu, por força de lei, em 1985, mas continuou Lacaz até o último de seus dias na Casa de Arnaldo, nela desenvolvendo sua pesquisa científica e a ela dando o briIho de sua mente e o melhor do seu desempenho humano. Não há pessoa que tenha passado pela Casa de Arnaldo que não tenha recebido sua atenção, não há canto dessa casa que de perto ele não conhecesse.

A atividade de pesquisa de Lacaz foi extensa. Ela é marcada por suas contribuições à micologia médica e à patologia tropical, sendo de referência internacionalmente obrigatória. Em muitos dos seus livros expõe a sua experiência nessas áreas, notadamente em suas Lições de Micologia Médica (São Paulo, 1953) e em Introdução à Geografia Médica no Brasil, que preparou com Baruzzi e Siqueira Júnior (São Paulo: Blücher / EDUSP, 1972) . Seu traço huma- nístico marca outros de seus livros, frutos do brilho de sua atividade intelectual incessante, como aqueles voltados à história da medicina, entre os quais se destacam os textos reunidos nos volumes de Vultos da Medicina Brasileira (São Paulo: Pfizer, 1963-1977).

Grande didata, Lacaz introduziu a ilustração clínica no curso de microbiologia e imunologia da FMUSP, estimulando o interesse dos seus alunos pela matéria. A partir de 1954, Lacaz organizou e ministrou o curso anual de especialização em Medicina Tropical da FMUSP, que rapidamente alcançou foro internacional. Este curso criou o ambiente para que Lacaz conseguisse criar, em 1959, na FMUSP, o Instituto de Medicina Tropical de São Paulo. Lacaz plasmou esse instituto e o dirigiu enquanto Professor. Esta modelar instituição de ensino e pesquisa projeta, por todo o mundo, o cultivo da especialidade nele efetuado. Esse mesmo centro, desde sua criação, passou a publicar a hoje tradicional Revista do Instituto de Medicina Tropical de São Paulo.

Lacaz foi Diretor da FMUSP (1974-1978), cargo que exerceu com modelar dedicação. Reformulou o ensino. Criou novas vagas para a carreira universitária, abrindo os horizontes para novos docentes, entre os quais dezessete novas posições de professortitular, uma das quais destinada à Neurologia. Criou o Museu da FMUSP (desde 1999, Museu Carlos da Silva Lacaz), do qual foi Diretor Vitalício. Deu foro ao tombamento da Casa de Arnaldo, gigantesca tarefa que concluiu enquanto a dirigia. Definiu e re- 
gulamentou os Laboratórios de Investigação Médica (LIM) do Hospital das Clínicas da FMUSP, com os quais procurou-se dotar a instituição de um liame com a pesquisa médica básica, já que destas fora privada a escola pelo novo estatuto da Universidade de São Paulo.

Entre os LIM, destaca-se o muito que fez pela neurologia. Iniciado em 1973 como Centro de Investigações em Neurologia (CIN), este conjunto de laboratórios da FMUSP passou a integrar o LIM-15 (Laboratório de Investigação em Neurologia). Nele, não houve pesquisa de neurologia tropical e de neuroinfectologia para a qual não tivesse Lacaz ativamente contribuído. Para todos os seus integrantes manteve sempre abertas as possibilidades de recursos de pesquisa do Instituto de Medicina Tropical e, posteriormente, do LIM de Micologia Médica, que Lacaz dirigiu e no qual pesquisou e formou novos pesquisadores até o último de seus dias.

Se há uma realidade brasileira no estudo das neuromicoses, isto certamente traduz a linha de pesquisa clínico-laboratorial adotada por Lacaz. A importância desse modo de conduzir a pesquisa ganha ênfase com a sistematização do estudo das micoses do sistema nervoso em situações de imunodeficiência, como na síndrome da imunodeficiência adquirida. Basta lembrar, a propósito, o quanto contribuiu Lacaz para os estudos sobre a neurocriptococose e sobre a neuroparacoccidioidomicose desenvolvidos no CIN e, também, em outros centros de neuroinfectologia brasileiros. Sem exceção, em todos sua presença era uma realidade, quer por seus ensinamentos, quer por seus discípulos que atuam nesses centros.

A presença científica de Lacaz, seguramemte, não se fez sentir apenas na neurologia. Ela se encontra em toda a comunidade científica do país, entre seus alunos, cada um deles seu discípulo. Somam eles algumas centenas, às quais se acrescem mais que uma centena provenientes de outros países, particularmente da América Latina. Cada um deles encontrou em Lacaz um modelo a seguir, um verdadeiro amigo com quem repartir dúvidas científicas e em quem buscar orientação para os passos da carreira universitária e, também, para seus problemas pessoais. Cedo, todos entreviam em Lacaz a ética hipocrática que, como uma aura, o circundava e, sem mácula, com entusiasmo ditava seus atos.

Essa mesma ética e esse mesmo entusiasmso nortearam as pelejas universitárias de Lacaz para salvar a Casa de Arnaldo do desmantelamento a que fora condenada. Foi com muita fé e coragem que Lacaz empreendeu sua luta contra esse vaticínio. A propósito, Lacaz escreveu sobre o que denominou "a mutilação da Faculdade de Medician, texto que consta de sua obra História da Faculdade de Medicina - USP (São Paulo: Atheneu, 1999). Ao findar seus dias, já se avistava a luz da vitória. Hoje, a pesquisa médica básica é um fato na Casa de Arnaldo. Cumpre aos seus continuadores darmos o molde a essa nova fase da FMUSP, mais que tudo através do seu Hospital das Clínicas.

Dos muitos lauréis que a vida lhe trouxe, ser da Casa de Arnaldo foi aquele que com mais orgulho Lacaz ostentava. Basta lembrar com que emoção recebeu ele a homenagem que lhe prestaram os funcionários da FMUSP em seu último aniversário, de que participaram seus colegas da Casa e seus familiares. A estes últimos, Lacaz, como sempre fez, dedicou a homenagem. Sua esposa, Dinah Maria Martins Lacaz, e seus filhos Carlos Roberto, Ana Helena, Carlos Augusto e Carlos Eduardo são as jóias da coroa do arauto da Casa de Arnaldo, o Prof. Dr. Carlos da Silva Lacaz. 